\title{
Behavior during Childhood
}

National Cancer Institute

\section{Source}

National Cancer Institute. Behavior during Childhood. NCI Thesaurus. Code C90346.

Observed actions from individuals between 2 and 18 years of age. 